\title{
The Nature of Innovation Eco-System of the Western Kazakh State University
}

\author{
Liliya Mergaliyeva $^{1}$ \\ ${ }^{1}$ West Kazakhstan State University, Kazakhstan \\ Correspondence: Liliya Mergaliyeva, West Kazakhstan State University, Kazakhstan. Nazarbayev str. 162/2, Uralsk.
}

Received: May 27, 2020

Accepted: June 22, 2020

Online Published: June 25, 2020

doi:10.5430/ijhe.v9n4p254

URL: https://doi.org/10.5430/ijhe.v9n4p254

\begin{abstract}
During the COVID-19 pandemic, universities have quickly and effectively moved millions of students and educators online despite huge logistical and technological challenges. There are very few industries that have reacted in this way. In future leading universities will look for a new business model and apply disruptive innovations into the leaning process.

In recent years Kazakh higher education development has been accompanied by intensive economic growth thereby raising demand for high qualified employers. The aim of this research was to reveal the ways of implementing high innovation and creativity approaches at Western Kazakhstan State University. This study examined the factors determining conditions for development of an innovative culture across the university and industry. The methodology is based on semi-structured interviews, reflective experiences; survey of students, teachers and administration. The results show that WKSU needs frugal innovation, as it provides a new entrepreneurial landscape for companies in low-income countries with limited resources to develop innovations.
\end{abstract}

Keywords: innovation value chain, corporate entrepreneurship assessment instrument, higher education, strategy, PESTEL, Kazakhstan

\section{Introduction}

The infrastructure of universities aims to provide a free access to the data related to education and research as well as to support entrepreneurship and innovation (Amabile et al. 1996; Christensen et al. 2011). Haynes (2002) and Jones (2010) state in their research that professors, students, researchers and as well as management boards demonstrate a crucial influence to the development of an innovation eco-system. Employees who have high extraversion traits are more creative and intuitive (Digman and Inouye 1986; Stavridou and Furnham 1996; McCrae and Costa 1997; Wolfradt and Pretz 2001; Furnham and Bachtiar 2008). University policy and innovative thinking underlines that policy requirement is to provide cross industries collaboration within a national system of innovation (Kruss, 2005). It has been proven that there is the direct connection between research activity and economic performance as "the centrepiece of all scientific and technological efforts" (Manzini 2012, p.6).

The multiple government organizations in Kazakhstan focus on innovation developments in universities: Science, Engineering and Technology Institutions, the National Advisory Council on Innovation (NACI), the Ministry of Education and Science, and the Ministry of Trade and Industry. These authoritative bodies stimulate joint industry-academic research initiatives (OECD 2013) and accelerate knowledge economy (Kahn, Qualter, Young, 2012).

The results of academic knowledge via publications could find the way to businesses and stakeholders for realization. Ideally, the innovation policy encourages researchers to take part in the setting up start-up of their own spin-off companies (Bartell 2003; Brewer and Tierney 2010). Reward for the activity of researchers-who provides a transfer of knowledge to society or innovations, is known as a productive measure (Hage and Meeus 2006). As a rule the university have to support professors and students in establishing start-ups and own business and the foundation of development laboratories (OECD 2011; Laursen and Salter 2006; Christensen et al. 2011). However, according to the OECD (2017) report governments do not provide tax incentives for research and development, and direct government support for innovative initiatives. This problem seriously impacts Kazakhstan's universities as they bear a responsibility for boosting and converting innovations into the economy. Sung and Choi (2012) report that charisma and personality as well as experimental nature provide an essential effect on performance and improves 
innovation. Leaders have to be much more open to information and welcoming to news, even if it's bad news. They should be candid and probing, and a little less focused on operational excellence.

The innovation ecosystem at the West Kazakhstan State University (WKSU) began in 1932 when the university offered its first courses. WKSU has a Development strategy 2030, which increases the diversity of the system by fostering radical new insights, inventions and incremental innovation. WKSU is a nonprofit public higher education organization. The university consists of six institutions, 50 undergraduates' degree specialties, and 26 post graduates. The number of WKSU's students was 5725 in 2019/2020 educational year, which is $10 \%$ of all students in Kazakhstan. However, it is not a full capacity of the university as it has 12000 students in 2004 . WKSU has the ranking $8^{\text {th }}$ place in the list of universities in Kazakhstan by performance and quality (WKSU, 2020). University has the admission rate range at 50-60\% making WKSU an averagely selective institution. WKSU's infrastructure includes 8 buildings, 1 dormitory, 2 gyms, country base, a publishing center, and a library exceeding one million books. University has AIS Platonus which provides updated information about university's activity, staff, courses, student's records and conducts distance learning programs.

This paper explores the nature of innovation eco-system of the WKSU. The following research questions have been explored: 1. Is there an innovation culture in the university? 2. Which is the right innovation strategy for WKSU?

\section{Method}

In order to assess the innovation culture at WKSU, it is pertinent to familiarize with social, political and economical environment both within and outside the university. It is also important to consider the transformational journey of an idea to an executable product and to evaluate the support an idea harness from management at various stages of its journey.

In a PESTLE analysis, it is demonstrated how various Political, Economic, Social, Technological and Legal factors affect a given industry. This analysis can be used to understand the external eco-system of the university.

Innovation Value Chain IVC model consists of three broad phases how to generate, transform and disseminate ideas. Within each phase are activities that involve collaboration, screening and developing, and spreading ideas within and outside the organization. These new ideas may be incorporated in the system for novelty and creativity which simultaneously leads to innovation.

The Corporate Entrepreneurship Assessment Instrument helps to assess the internal organization in five dimensions, namely management support, work discretion, rewards, time availability and organizational boundaries (Kontić, Vidicki and Domanović, 2017).

The research was conducted using analysis of PESTLE framework, Innovation Value Chain ( IVC) model (Hansen and Birkinshaw, 2007) and the Corporate Entrepreneurship Assessment Instrument (CEAI) (Kuratko and Hornsby, 2014). A questionnaire survey was conducted with 83 respondents of WKSU staff (senior and medium) and 35 students. The staff have been employed a minimum of one year in WKSU and have three years of experience in higher education.

\section{Results}

\subsection{WKSU'S Industry Overview}

The total number of students in 124 universities of Kazakhstan is 542458 in 2019 (Statistical Committee of Kazakhstan, 2020). The student's funds have been primarily provided by private budget and $30 \%$ of all students receive full scholarships and stipend (Statistics Committee of Kazakhstan, 2020).

\subsection{External Environment Analysis PESTEL}

\section{Political}

Kazakh government is slowly cutting down on its education budget, which could prove a serious problem for universities in the future. The weight of higher education remains at $1.6 \%$ of the state budget (Statistics Committee of Kazakhstan, 2020). It is planning to create a Central Asian educational hub with the best educational programs, leading professors, branches of the international universities. Kazakh HEIs enroll about 14,000 foreign students from Uzbekistan, Turkmenistan, Kyrgyzstan, China, India, and other countries. The number of international students is expected to reach 50,000 by 2025. State Program of Education Development for 2016 - 2022 aims to enhance HEIs' competitiveness, ensure that graduates are fit for the industrial and innovative development of the country. Kazakh government has been launching technology transfer and commercialization support programs too. 
Since 1993 Bolashak Scholarship assists talented young people in obtaining quality education abroad. The Bolashak program currently has agreements with 33 countries and 200 educational institutions worldwide; it has more than 10,000 graduates.

\section{Economical}

According to the World Bank (2020), Kazakhstan has not seen significant progress towards the formation of an innovative economy. The index KEI (the level of application of knowledge in the economy), is very low. There is a real problem to provide a job to many high-qualified experts, as the economy moves from industrial to knowledge economy, ignoring service economy stage. Fall of crude oil price, raise of inflation, growth of interest rate, devaluation of national currency, slow economic growth, lock down due to Covid-19 has the potential to change the educational market. As a result more high school graduates might jump straight into their working lives.

\section{Social}

The impact of social and cultural distance between countries is decreasing (Buchan, Grimalda, 2011). Kazakh high school graduates are willing to study in UK, US, Europe or any other country. These students may doubt why they would want to study in Kazakhstan if they can study elsewhere and have better-paid career prospects. Demographic growth will benefit Kazakh education system in the next 10 years (Statistics Committee, 2020).

\section{Technological}

Massive Open Online Courses (MOOCs), such as Khan Academy, Coursera (35 million of users), Udemy (10 dollar lessons per course), Udacity, and edX, would challenge F2F university education as digital technologies removed the jobs of telephone operators and travel agents (HBR, 2020) Artificial Intelligence or Virtual Reality could unprecedentedly change the traditional way of learning at higher education institutions. Up to 800 million global workers may lose their jobs by 2030 and be replaced by robotic automation (McKinsey Global Institute, 2017).

\section{Legal}

A state attestation, public control, certifications and institutional accreditation from independent accreditation associations have projected a huge influence on industry. Ministry of Education and Science of the Republic of Kazakhstan maintains strict supervision.

\section{Environment}

Main trends are green construction, eco- campus planning, eco-friendly equipment and facilities, natural capital improvement. Universities have to demonstrate a sustainable approach to the environment and become an example of excellent implementation of standards of sustainability.

\subsection{Innovation Value Chain Analysis}

The management professionals, teaching staff as well as students answered 12 questions (Note 1). Questionnaire Survey Results demonstrates that each of three sections has a "poor" innovations scope, as numbers are more than average rate 2.38 indexes (Table 1 ).

Table 1. IVC survey Indexes by level of management in WKSU, 2020

\begin{tabular}{lllll}
\hline Categories of Innovation in an Organisation & $\begin{array}{l}\text { Senior } \\
\text { Management }\end{array}$ & $\begin{array}{l}\text { Middle } \\
\text { management }\end{array}$ & Students & Average \\
& Poor 2,5 & Poor 2,5 & Poor 2,2 & 2,4 \\
\hline 'Idea Poor Company' & Poor 2,5 & Poor 2,3 & Poor 2,5 & 2,4 \\
'Conversion Poor Company' & Poor 2,6 & Poor 2,3 & Poor 2,6 & 2,5 \\
'Diffusion-Poor Company' & 2,5 & 2,4 & 2,4 & 2,4 \\
Total IVC & nat & &
\end{tabular}

$40 \%$ of respondents found the present ecosystem as not friendly for new ideas. The new ideas comes from the external environment ( $42 \%$ strongly agree), and colleagues tend to accept those ideas (42\% strongly agree). The diffusion of innovations goes very slowly and only $8 \%$ agrees that university is not covering all markets, new markets. It means it misses the opportunity to expand the services for the whole country and neighbourhood. $73 \%$ of employees expressed an opinion that competitor copy the products and services. It shows that the ecosystem of innovations lacks proper diffusion of its services and products. The speed of implementing of new ideas into education process is also very slow, and $80 \%$ of university staff experienced this problem according to survey.

\section{Strength and Weaknesses}


Senior and Junior staffs have capability to innovate and develop the existing components of WKSU. Also, Innovative ideas can be found across all the departments and units of the university but raising fund to execute these ideas can be a big challenge.

Even through innovation across teaching methods and courses offered can be attractive but it remains susceptible to copy by other universities.

\subsection{CEAI Questionnaire Survey}

Table 2. CEAI survey Indexes by level of management in WKSU, 2020

\begin{tabular}{|c|c|c|c|c|}
\hline Organisational factors & $\begin{array}{l}\text { Senior } \\
\text { Management }\end{array}$ & $\begin{array}{l}\text { Middle } \\
\text { management }\end{array}$ & Students & Average \\
\hline $\begin{array}{l}\text { Management support for corporate } \\
\text { entrepreneurship }\end{array}$ & Good 3,9 & Poor 2,6 & Poor 1,8 & Poor 2,8 \\
\hline Work discretion & Good 3,9 & Poor 2 & Poor 2,3 & Poor 2,7 \\
\hline Rewards/Reinforcement & Good 4 & Good 3,8 & Poor 2,3 & Neutral 3,4 \\
\hline Time availability & Good 4,7 & Good 3,8 & Poor 2,2 & Good 3,6 \\
\hline Organizational boundaries & Good 4,6 & Good 3,7 & Poor 3 & Good 3,8 \\
\hline Total CEAI score & Good 4,22 & Poor 3,18 & Poor 2,32 & Neural 3,24 \\
\hline
\end{tabular}

WKSU's CEAI Questionnaire Survey Results are reflected in the table 4 and compared with the average rate of 3.24. Management support for entrepreneurship got 2.8, work discretion 2.7, rewards 3.4, time availability 3.6 and organizational boundaries 3.8. There are strengths and weaknesses in entrepreneurship culture of WKSU in table 2.

\section{Strength and Weakness}

Even through young employees have the talent and problem-solving abilities, they require more support from top management to develop ideas into tangible outcomes. Ideas emerge within each departmental unit but to develop an idea having significant impact, organizational boundaries should be weakened through collaboration. Effective rewards and recognition system should be in place to translate the passion for the emerging idea into a goal which is sustainable and pursuable.

\subsection{Interviews with $\mathrm{COO}$ - Head of Economics and Management Department and Head of Commercialization} Centre

In order to provide more accurate analysis, two university employees were interviewed. First, the Head of Economics and Management Department at WKSU was interviewed. She accepted the fact that new ideas can come outside of the university and would become friendlier to implement them. The interviewer agreed that a restricted capital at university constrains the funding of the projects. However, she also added that remuneration system has stimulated faculty to published papers in A, B ranked journals. She stated that new methods of teaching improved students' creativity and autonomy, for example, problem-and project-based learning, research methods, actualization of creative potential and independence students (WKSU, 2020).

Second, Head of Commercialization centre said that Intellectual Property is highly valuable activity in the university. He realized that there is a need in highly evolving faculty, who can be tech oriented in terms of delivering understanding of technology. It must require some time to develop a culture, where people generate and execute new ideas and learn how to commercialize them. He mentioned that the human potential during the years has been not only quantitatively reduced, but also significantly "aged." In university, the acute problem is the lack of experts on the organization of innovation, science and technology, economic assessment, evaluation and use of intellectual property, commercialization of research (WKSU, 2020).

\section{Discussion}

WKSU has 450 employees, $36 \%$ of staff has academic degree ( $\mathrm{PhD}$, candidate and doctor of science). The average age of faculty members is around 52.5 years. The problem of ageing staff brings lack of creativity and possibilities of new ideas or innovations. The staff of university has weak relations with manufacturing companies or business entities; they have no connection with industry certification programs. WKSU has a system of financial and non-financial rewards for publication activity as well as English language certification (IELTS). The motivations are both intrinsic and extrinsic. The university pays approximately 500 US dollars for paper in non-zero impact factor 
journal, for IELTS/TOEFL - 50 US dollars. This university produces staff ranking; top employees benefit from non-financial support (longer vacations, convenient tame-table, recognition and praising). Despite the university has adequate grading and reward systems for innovative initiatives, literary, professors/assistant professor could not often publish papers in A/B rated journals because they find it difficult to research globally as have a lack of English language.

It is recommended to decide innovation strategy of WKSU from determine goals based on business objectives, capabilities, market contexts, structure, culture. It should have understood of place and importance of innovation strategy in the university eco-system. From top level innovation strategies - Play not to lose - is the right strategy for WKSU (Afuah, 2013). It is focusing on incremental innovation through which university can slowly build up its competitive position. However, Davila et al (2013) highlighted two dangers of this strategy, in case other universities will adopt a more aggressive PTW strategy and PNTL strategy steadily becomes a 'follower' strategy.

Once WKSU has realized the need for innovation, and allocated capital for conceptualizing and executing new innovative ideas, it is a dilemma whether the university needs to move to disruptive (Chamorro-Premuzic, 2019) or apply frugal innovations (Hossain, 2020). It is recommended to go for frugal innovation, as it provides a new entrepreneurial landscape for companies in low-income countries with limited resources to develop innovations. It also contributes to sustainability.

It is about creating new models for school learning as improvement of ways of teaching, usage of distant learning platforms, transform and involving disruptive technologies as AI, and machine learning. However, WKSU has lack of innovations funding. DO more with LESS is adequate approach for the university in emerging economy.

The Fourth Industrial Revolution will require us to implement the best practices of innovation. There 5 areas of Innovations focus in WKSU:

- Improvement of online remote courses and programs delivery, which is infused with traditional academic processes.

- Long-term cooperation benefit between industry and academia.

- Enhancement of modules to prepare student for the Gig Economy — including consultants, independent contractors, freelancers, side giggers.

- Provide a lean learning. 1. Learning the core of what you need to learn 2. Applying it to real-world situations immediately 3. Receiving immediate feedback and relearning your understanding 4. Repeating the cycle. Lean learning ensures that students not only learn the right thing, at the right time, and for the right reasons, but also that they retain what they learn. (HBR, 2019)

- Movement towards knowledge creation through research rather than teaching. This could mean that for academics, it will become more important than ever to focus on research.

WKSU should rethink its current position and implement technological innovations in frugal way that will prepare students for new labor market, develop sustainable values and project beneficial effect to the community. Innovation needs to be considered a continuous capability in a university that's built for transient advantage, embedded in the organization. Management staff should have an innovative entrepreneurial approach to education and research. The leader in the university is a key factor, who has a long-term vision of innovations and understands the strategy of its implementation.

\section{Acknowledgements}

This paper draws on my research at University of Warwick, Warwick Business School. I am sincerely grateful to our Innovations and Creativity course leaders, professors Guiliana Battisti and James Hayton.

\section{References}

Afuah, A. (2009) Strategic innovation: New game strategies for competitive advantage, Strategic Innovation: New Game Strategies for Competitive Advantage. https://doi.org/10.4324/9780203883242

Amabile, T. M. (1996) ‘The motivation for creativity in organizations', Harvard Business Review, January.

Bartell, M. (2003) 'Internationalization of universities: A university culture-based framework', Higher Education. https://doi.org/10.1023/A:1021225514599

BBC Report (2017) Robot automation will 'take 800 million jobs by 2030' - report - BBC News, BBC .

Brewer, D. J. and Tierney, W. G. (2011) 'Barriers to innovation in U.S. higher education', in Reinventing higher education: The promise of innovation. 
Brillinger, A. S. et al. (2019) 'Business model risk and uncertainty factors: Toward building and maintaining profitable and sustainable business models', Business Horizons. https://doi.org/10.1016/j.bushor.2019.09.009

Buchan, N. R., \& Grimalda, G. (2011). Reducing social distance: The role of globalization in global public goods provision. In Advances in Group Processes. https://doi.org/10.1108/S0882-6145(2011)0000028009

Chamorro-Premuzic, T. And Frankiewicz, B. (2019) '6 Reasons Why Higher Education Needs to Be Disrupted', Harvard Business Review.

Christensen, C. et al. (2011) 'Disrupting College', Center for American Progress. https://doi.org/10.1306/74D70D8F-2B21-11D7-8648000102C1865D

Digman, J. M. and Inouye, J. (1986) 'Further Specification of the Five Robust Factors of Personality', Journal of Personality and Social Psychology. https://doi.org/10.1037/0022-3514.50.1.116

Ebbinghaus, H. (2013) 'Memory: A Contribution to Experimental Psychology', Annals of Neurosciences. https://doi.org/10.5214/ans.0972.7531.200408

Furnham, A. (2019) 'Personality and individual differences', in The Psychology of Behaviour at Work. https://doi.org/10.4324/9780203506974-4

Furnham, A. and Bachtiar, V. (2008) 'Personality and intelligence as predictors of creativity', Personality and Individual Differences. https://doi.org/10.1016/j.paid.2008.06.023

Glaveski, S. (2019) 'Where Companies Go Wrong with Learning and Development', Harvard Business Review.

Govindarajan, V. and Srivastava, A. (2020) What the Shift to Virtual Learning Could Mean for the Future of Higher Ed, Harvard Business Review.

Hackman, J. R., \& Oldham, G. R. (1976). Motivation through the design of work:Test of a theory. Orga- nizational Behavior and Human Performance, 16, 250-279. https://doi.org/10.1016/0030-5073(76)90016-7

Hage, J. and Meeus, M. (2006) Innovation, Science, and Institutional Change, oxford university press on demand.

Hansen, M. and Birkinshaw, J. (2007). The Innovation Value Chain. [online] Harvard Business Review. Available at: https://hbr.org/2007/06/the-innovation-value-chain [Accessed 21 Apr 2020].

Hayton, J. and Kelley, D. (2006). A competency-based framework for promoting corporate entrepreneurship. Human Resource Management, 45(3), 407-427. https://doi.org/10.1002/hrm.20118

Hossain, M. (2020) 'Frugal innovation: Conception, development, diffusion, and outcome', Journal of Cleaner Production. https://doi.org/10.1016/j.jclepro.2020.121456

INSEAD Knowledge. (2007). The innovation value chain. [online] Available at: https://knowledge.insead.edu/innovation/the-innovation-value-chain-2161 [Accessed 21 Apr. 2020].

Kahn, P., Qualter, A. and Young, R. (2012) 'Structure and agency in learning: A critical realist theory of the development of capacity to reflect on academic practice', Higher Education Research and Development. https://doi.org/10.1080/07294360.2012.656078

Kontić, L., Vidicki, D. and Domanović, V. (2017). Testing corporate entrepreneurship assessment instrument in transition environment. Dubrovnik International Economic Meeting, [online] 3(1). Available at: https://search.proquest.com/openview/54ac99ba628c233d8c2d6072dcd69bbe/1?pqorigsite=gscholar\&cbl=2049 763 [Accessed 22 Apr 2020].

Kruss, G. (2005) 'Distinct pathways: tracing the origins and history of private higher education in South Africa', Globalisation, Societies and Education. https://doi.org/10.1080/14767720500347668

Manzini, E. (2012) 'Error-friendliness: How to deal with the future scarcest resource: The environmental, social, economic security. that is, how to design resilient socio-technical systems', Architectural Design. https://doi.org/10.1002/ad.1429

McCrae, R. R. and Costa, P. T. (1997) 'Personality Trait Structure as a Human Universal', American Psychologist. https://doi.org/10.1037/0003-066X.52.5.509

Mulcah, D. (2019), 'Universities Should Be Preparing Students for the Gig Economy', Harvard Business Review.

Petersen, I. haam and Kruss, G. (2019) 'Promoting alignment between innovation policy and inclusive development in South Africa', Development Southern Africa. https://doi.org/10.1080/0376835X.2018.1490175 
Pisano, G. (2015). You Need an Innovation Strategy. [online] Harvard Business Review. Available at: https://hbr.org/2015/06/you-need-an-innovation-strategy [Accessed 19 Apr. 2020].

Reason, P. and Hawkins, P. (1988) Human Inquiry in Action: Developments in New Paradigm Research, Human Inquiry in Action: Developments in New Paradigm Research.

Rouhiainen, L.(2019) 'How AI and Data Could Personalize Higher Education', Harvard Business Review.

Sensenig, V. J. (2009) 'Changing education: leadership, innovation and development in a globalizing Asia Pacific', Compare: A Journal of Comparative and International Education. https://doi.org/10.1080/03057920903138548

Statistics Committee of Republic of Kazakhstan (2020) “Higher Education in Kazakhstan", https://e-gov.stat.kz

Sung, S. Y. and Choi, J. N. (2012) 'Effects of team knowledge management on the creativity and financial performance of organizational teams', Organizational Behavior and Human Decision Processes. https://doi.org/10.1016/j.obhdp.2012.01.001

Theos, E., David, R., Hardoon, Ovchinnikov, A. (2020) 'Leveraging AI to Battle This Pandemic - And The Next One', Harvard Business Review.

Tyagarajan, T.(2019) 'To Prepare for Automation, Stay Curious and Don’t Stop Learning', Harvard Business Review.

Western Kazakhstan State University Innovation Culture (2020) https://20.wksu.kz/index.php/en/

Wolfradt, U. and Pretz, J. E. (2001) 'Individual differences in creativity: Personality, story writing, and hobbies', European Journal of Personality. https://doi.org/10.1002/per.409

Wood, M. G., Smith, D. I. and Hayns, M. R. (2002) 'The sinking of the lusitania: Reviewing the evidence', Science and Justice-Journal of the Forensic Science Society. https://doi.org/10.1016/S1355-0306(02)71822-4 